crash into our textbooks of physiology and of information theory. But most thinking neurologists look askance at all cerebral diagram-makers and cartographers, whether they tell of cortical architectonics, motor homunculi, suppressor bands, or linguistic schemata. Mindful of the fate of phrenology, modern neurology has but little respect for cerebral mosaics.

How then should we judge Gall to-day, after we have divorced the accomplishments of the man from the record of his phrenological votaries? Gall represents a " great though misguided, and perhaps even slightly ridiculous, figure in the rise of a progressive science." This, according to Temkin, was the verdict of the historians of philosophy, Littre and Lewes. Perhaps they were a little too hard. To contemporary neurologists Gall was a great man.
May I, in conclusion, quote that inspiring anatomist, the mentor of so many of us older medical scientists? "The time has come," he wrote, "for a juster appreciation of the important part played by Gall, and a more adequate recognition of his achievements than has been made in the past. If he was responsible for certain speculations, which in the hands of irresponsible followers have been used for meretricious purposes, it must not be forgotten that Gall's work brought to an end a barren system of philosophy which seriously impeded progress. His contributions to the anatomy of the central nervous system are of far-reaching importance, and to the physiology of the brain and to psychological theory he gave a new orientation and a new inspiration." These were the words of Elliot Grafton Smith, with which you and I might perhaps agree.

\title{
Bleeding Peptic Ulcer
}

\author{
ANNE BANNING,* M.B., M.R.C.P. ; ANTHONY BARON, † M.CHIR., F.R.C.s. ; HARRY KOPELMAN, $\ddagger$ M.D., F.R.C.P. \\ K. L. LAM, $\S$ M.B., M.R.C.P.GLASG.; PELHAM WARREN, † M.B., F.R.C.S.
}

Brit. med. F., 1965, 2, 781-784

In the past 30 years few conditions have provoked wider divergence of opinion upon treatment than bleeding from peptic ulcer. Before the last war the tendency was to follow the practice of Meulengracht (1935) and to treat this condition conservatively. However, some surgeons, notably Finsterer, were reporting good results from the early employment of surgical treatment. In the years that followed the war certain indications for surgical treatment came to be fairly generally accepted (Gordon-Taylor, 1946). These indications form the basis of treatment in most centres to-day and are: (1) severe pain preceding or persisting after the haemorrhage, (2) recurrent bleeding, and (3) an age of over 50, particularly should there be obvious evidence of arteriosclerosis. To this list to-day one would add continued bleeding and the coexistence of haemorrhage and perforation. There has been an underlying assumption that these indications apply only in cases of chronic peptic ulcer, and a good deal of attention has been directed to distinguishing acute from chronic ulcer. Since the history is often misleading, resort has been made in some centres to special investigations such as gastroscopy and barium examination in the bed (Chandler et al., 1960). Surgical treatment has been by partial gastrectomy, whether the source of- bleeding is demonstrated at the operation or not.

We have for some years accepted the usual criteria for intervention-that is to say, severe repeated or continuous bleeding-but have, as a result of experience over 10 years or so, learned to regard the chronicity or otherwise of the ulcer as irrelevant and have adapted the surgical procedure to the condition found at operation. In the past five years 223 patients with haematemesis and melaena thought to be due to peptic ulceration have been treated, and in this paper the results of treatment are analysed.

\section{Material and Management}

All of the patients in this series were admitted to hospital in one five-year period, and are those in whom there was direct evidence of haematemesis or melaena, sufficient to cause a moderate-to-severe fall in haemoglobin at some time, either immediately before or after admission. We have included all cases of bleeding from peptic ulcer and also from carcinoma of the stomach and hiatus hernia when these were admitted for bleeding and when the diagnosis was not already known. We have excluded cases of haematemesis and melaena from other causes such as oesophageal varices, bleeding diathesis, uraemia, and severe blood disorders. Patients with anaemia from gastrointestinal bleeding of a chronic nature have not been included, nor have those admitted with a history of haematemesis who showed no evidence of significant haemorrhage.

All the patients admitted were kept under close observation. If restless or anxious they were given phenobarbitone by injection. Adequate hydration was assured and the diet was of milk or of a semi-solid nature. Routine investigation on admission included the examination of a direct blood smear, grouping and cross-matching of blood, and the estimation of serum electrolytes and blood urea. The haemoglobin level was estimated on admission and again after some hours. Halfhourly pulse rate and blood-pressure recordings were taken. In the earlier days hourly aspirations of stomach contents were carried out, but many patients became restless during this procedure and in recent years it has been discontinued. Observation was kept for any rise in pulse rate or fall in bloodpressure, but earlier indications of further bleeding were often given by subjective complaint of nausea or of a feeling of faintness, accompanied by sweating. In some cases the first evidence of further bleeding was a large vomit of bright blood without any warning.

There was no standard level of haemoglobin at which blood transfusion was started, as it was often difficult to establish the amount of haemoconcentration present, but, generally speaking, blood was given if the haemoglobin was below $60 \%$ on admission. If a further severe haemorrhage occurred after admission-as evidenced by direct observation of fresh blood vomited or fresh bright melaena, or by a rise in pulse rate and fall in blood-pressure, or in some cases by a falling haemoglobin level despite repeated blood transfusion-this was taken as an

* Former Medical Registrar, St. Margaret's Hospital, Epping, Essex. $\dagger$ Surgeon, St. Margaret's Hospital, Epping, Essex.

§ Former House-physician, St. Margaret's Hospital, Epping, Essex. 
indication for early operation whether the history was suggestive of chronic ulceration or not. In patients with rhesusnegative blood groups there was a bias towards early operation, since the supply of blood in these groups is a limiting factor in treating prolonged bleeding conservatively.

In the group of patients who were treated conservatively and whose progress was satisfactory a barium-meal examination was carried out in the $x$-ray department as soon as the patient's condition permitted this. All patients were subsequently followed up in the out-patient department for a minimum of six months.

\section{Surgical Approach and Procedure}

The indication for operating in these cases of gastrointestinal haemorrhage is the fact that haemorrhage is of sufficient severity to threaten life. The arrest of haemorrhage of this kind is one of the oldest functions of surgery, and the simplest means that will achieve the desired result should be employed. In these ill and often old and frail patients, both speed and gentleness are important, and for this reason a generous upper midline incision is to be preferred. Though this incision is, in general, unsatisfactory for routine adoption in upper-abdominal surgery because of the frequency with which incisional hernia follows its use, the extreme speed with which it can be made and closed are strong arguments for its employment in this type of emergency. Once the abdomen is opened a preliminary survey will show whether or not there is blood in the upper coils of the small intestine indicating that bleeding is continuing. The stomach and duodenum are inspected, and if there is no obvious lesion the lesser sac is opened so that the stomach may be carefully palpated between the fingers in the lesser sac and the thumb on the anterior surface of the stomach. Should there be no palpable lesion in the stomach or first part of the duodenum, the duodenal loop containing the head of the pancreas is mobilized forward and a further careful inspection and palpation carried out from the pylorus as far as the crossing of the mesenteric vessels. In the original inspection of the stomach the presence of such lesions as hepatosplenomegaly and oesophageal varices has been noted.

If at this stage, and after examining rapidly the upper small intestine, no site of bleeding can be found, a wide gastrotomy is performed, an incision from 4 to 6 in. $(10$ to $15 \mathrm{~cm}$.) long being made, so that the interior of the stomach and duodenum may be directly inspected and palpated. In approximately $40 \%$ of the operated cases (see Table II) we have found acute or subacute ulcers which were quite impalpable from outside the stomach. In only two cases have we failed to find the source of the bleeding. Since we have found these ulcers so frequently they merit a detailed description.

Acute Ulcers.-The average ulcer is about $0.5 \mathrm{~cm}$. in diameter, and in the centre there is a small artery which is sometimes bleeding when the stomach is opened but which is more often found with clot in its mouth. The ulcers are usually situated fairly high on the lesser curvature or on the posterior wall of the stomach, and a careful search is necessary to find them. Occasionally two such ulcers have been found fairly close together. Sometimes the vessel in the centre of the ulcer can be felt like a grain of sand or a small lead shot, and palpation is often the most rapid method of identifying the lesion. Infrequently these ulcers may be found in the region of the pylorus, and on one occasion an acute ulcer was present in the duodenum. For inspecting the pylorus, duodenum, and cardia a sigmoidoscope may be used. The surgical treatment of bleeding from these ulcers is simple, consisting merely of the placing of an $x$ type of haemostatic stitch around the vessel in the centre of the ulcer crater. Either thread or catgut may be used for this purpose. The gastrotomy wound is then closed, as is the abdomen, without drainage. It is emphasized that the gastrotomy must be of adequate length to obtain the widest possible view of the interior of the stomach. The cut edge of the stomach bleeds freely, and we have found that temporary arrest of this bleeding can very suitably be carried out by the application of Millin non-toothed capsule forceps.

Chronic Ulcers.-Chronic gastric or duodenal ulcers will, as a rule, have been revealed by routine inspection and palpation without resort to gastrotomy. Both gastric and duodenal ulcers of sufficient size and chronicity to be visible and palpable from without will probably require gastrectomy for the control of bleeding. So far as the surgical treatment of bleeding from chronic gastric and duodenal ulcer is concerned, our practice does not differ from that generally accepted. For gastric ulcer, gastrectomy is preferably performed with the Billroth I anastomosis. The Polya operation is appropriate for duodenal ulcer, and for the very large adherent or oedematous ulcer prepyloric section may provide a safer solution than an attempt to dissect the ulcer and obtain a closure beyond it.

\section{Findings and Results}

The age and sex incidence and the number of operations in each age and decade are shown in the Chart. In Tables I and II the 223 patients are considered in two groups in relation to the age of 60 . Of the men treated, 95 were under 60 and 47 over that age. The proportion of women of 60 and over was relatively higher: 43 out of a total of 81 . Approximately twothirds of the men gave a definite history of chronic ulcer compared with about half of the women. However, the proportion of chronic-ulcer lesions diagnosed by subsequent barium examination was approximately the same in both sexes and was about a half. Roughly one-third of the patients of both sexes had recently taken aspirin in some form. About one-fifth of the patients were judged to require operation, the incidence being slightly higher in those under 60 years of age.

Table II shows the operative findings and the operative procedure adopted. Minimal operation indicates undersewing of the bleeding vessel without resection of the ulcer. In two patients the source of the bleeding could not be found, the gastrotomy incision was closed, and no resection was carried out. In neither case was there evidence of further bleeding. The acute ulcers were situated in the stomach, except for two which were juxtapyloric and were thought to be duodenal. In only two cases was more than one acute ulcer present ; in each case there were two ulcers, and these were adjacent to one another. Not infrequently an acute ulcer has been found high

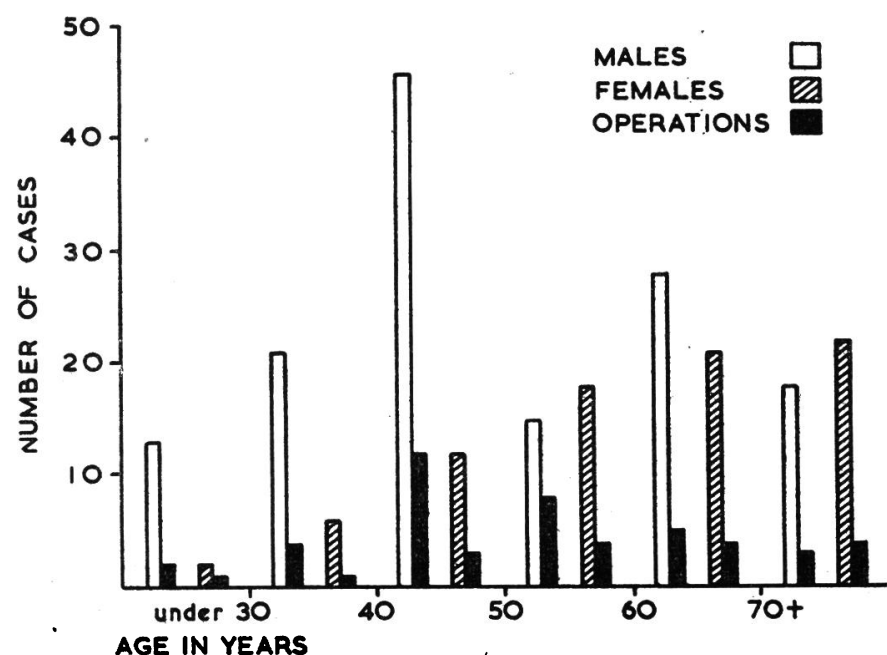

Age incidence of patients: the number of operations in each group is shown in the black column. The maximum age incidence in the men is in the 40-50 group, while in the women there is an increasing incidence with age. 
up in the stomach and above the likely level of section for "blind" partial gastrectomy.

In patients not treated surgically the number of chronic duodenal ulcers subsequently found was four times the number of chronic gastric ulcers. In the patients coming to operation the difference in incidence of chronic duodenal and gastric ulcer was less marked. Only one patient was operated upon within 12 hours of admission; a third of the patients were operated upon within 24 hours, and another quarter within 48 hours. In the remainder operation was delayed beyond 72 hours after admission. Post-operative complications, with two exceptions, caused no great anxiety. Five patients had post-operative chest infections, seven had wound infections, and three of the wounds required further suture. One patient had a small pulmonary embolus which produced no radiological evidence of infarction.

The two most seriously complicated cases required a further operation. One patient had had an acute gastric ulcer sutured and had made a normal recovery until he suddenly developed upper abdominal pain on the seventh day of convalescence. Laparotomy revealed a localized peritonitis due to perforation of an acute duodenal ulcer, after closure of which he made an uneventful recovery. The second patient bled initially from an acute gastric ulcer situated near the cardia, which was sutured. He developed a further serious haemorrhage some days after this operation, and at a second laparotomy another acute ulcer was found on the lesser curve, much lower than the original one. Subsequently he again bled seriously, and a third laparotomy showed yet another acute gastric ulcer in yet a different position. On this occasion, in addition to undersewing the ulcer, pyloroplasty and bilateral vagotomy were performed. A full exploration of the pancreas revealed no evidence of an adenoma. After a stormy convalescence the patient made a very good recovery and has had no further trouble in the year for which he has subsequently been observed.

The length of follow-up of patients who have undergone a minimal operative procedure has ranged from six months to several years, and in many cases barium studies have been carried out. There has been no evidence of the development of chronic ulceration and none of the patients has required further operative intervention.

Deaths.-These are shown in Table III. The criterion for inclusion in this group is that taken by Avery Jones (1947). All the deaths occurred in patients over 60 years of age and of the total of seven deaths three occurred during or after operation. In the other four cases no operation was carried out. The overall mortality for the whole group is $3.1 \%$.

TABLE III.-Details of the Deaths and Their Causes

\begin{tabular}{|c|c|c|c|c|}
\hline Sex & Age & Lesion & Operation & Cause of Death \\
\hline \multicolumn{5}{|c|}{ Operative } \\
\hline $\mathbf{F}$ & 83 & G.U. in hiatus hernia & Undersewing & \multirow{2}{*}{$\begin{array}{l}\text { Burst abdomen } 5 \text { day } \\
\text { post-op. } \\
\text { Died on table } \\
\text { Biliary peritonitis } 6 \\
\text { weeks later }\end{array}$} \\
\hline$\stackrel{M}{M}$ & $\begin{array}{l}72 \\
74\end{array}$ & $\begin{array}{l}\text { G.U. Hiatus hernia } \\
\text { Penetrating pyloric } \\
\text { ulcer }\end{array}$ & $\begin{array}{l}\text { Laparotomy } \\
\text { Gastrectomy and } \\
\text { partial pancrea- } \\
\text { tectomy }\end{array}$ & \\
\hline \multicolumn{5}{|c|}{ Non-operative } \\
\hline $\mathrm{F}$ & 76 & G.U. & Nil & \multirow{3}{*}{$\begin{array}{l}\text { Pulmonary embolism } \\
3 \text { weeks } \\
\text { Pulmonary embolism } \\
\text { C.V.A. } \\
\text { Haemorrhage }\end{array}$} \\
\hline $\begin{array}{l}M \\
M\end{array}$ & $\begin{array}{l}65 \\
67\end{array}$ & $\begin{array}{l}\text { Hiatus hernia } \\
\text { Ac. ulcer. Cong. }\end{array}$ & $\begin{array}{l}\text { Nil } \\
\text { Nil }\end{array}$ & \\
\hline $\mathrm{F}$ & 64 & $\begin{array}{l}\text { Pulmonary T.B. } \\
\text { Diabetes. C.V.A. } \\
\text { ?D.U. }\end{array}$ & Nil & \\
\hline
\end{tabular}

\section{Discussion}

The place of surgery in bleeding peptic ulcer, for long a matter of dispute, has since the war received some general measure of agreement. The clinical criteria have been, in the main, those of severe continued or recurrent bleeding from ulcers presumed to be chronic. It has been our experience that bleeding of this nature and severity may occur as readily from an acute or subacute ulcer as from a chronic one (Osborn, 1954). The differential diagnosis between bleeding from an acute and a chronic ulcer can be extremely difficult. Such ancillary investigations as gastroscopy and emergency barium meals may, at best, achieve an $80 \%$ accuracy in the first 24 to 36 hours (Chandler, 1960). The performance of these investigations is possible only in certain special centres, and in less expert hands might undoubtedly put a very considerable strain on an often exsanguinated and enfeebled patient. Our experience suggests that in any case this differentiation between bleeding from acute and chronic ulcer has no value in relation to management. The clinical assessment need only concern itself with the blood loss-its extent, and whether or not it continues or recurs.

TABle I.-Number of Cases in the Various Groups, Indicating Those in which a History of Chronic Ulcer was Definite, Equivocal, or Negative, the Findings at Subsequent Barium-meal Examination, and the Percentage Operated Upon

\begin{tabular}{|c|c|c|c|c|c|c|c|c|c|c|c|c|c|c|}
\hline & & & \multirow{2}{*}{$\begin{array}{l}\text { No. of } \\
\text { Cases }\end{array}$} & \multicolumn{3}{|c|}{ Chronic Ulcer History } & \multicolumn{5}{|c|}{ Barium-meal Examination } & \multirow{2}{*}{ Drugs } & \multicolumn{2}{|c|}{ Operations } \\
\hline & & & & Definite* & Equiv. & Neg. & G.U. & D.U. & H.H. & Cancer & Neg. & & No. & $\%$ \\
\hline Males & $\left\{\begin{array}{l}\text { Under } 60 \\
60+\ldots\end{array}\right.$ & $\because$ & $\begin{array}{l}95 \\
47\end{array}$ & $\begin{array}{l}63 / 45 \\
30 / 20\end{array}$ & $\begin{array}{l}5 \\
6\end{array}$ & $\begin{array}{l}26 \\
11\end{array}$ & $\begin{array}{l}9 \\
0\end{array}$ & $\begin{array}{l}35 \\
16\end{array}$ & $\begin{array}{l}4 \\
7\end{array}$ & $\begin{array}{l}1 \\
1\end{array}$ & $\begin{array}{l}31 \\
15\end{array}$ & $\begin{array}{l}\text { A27, B2, S1 } \\
\text { A18, B1 }\end{array}$ & $\begin{array}{r}24 \\
8\end{array}$ & $\begin{array}{l}25 \\
17\end{array}$ \\
\hline \multirow{2}{*}{ Females } & $\left\{\begin{array}{l}\text { Under } 60 \\
60+\ldots\end{array}\right.$ & 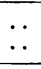 & $\begin{array}{l}38 \\
43 \\
\end{array}$ & $\begin{array}{l}25 / 22 \\
19 / 12 \\
\end{array}$ & $\begin{array}{l}6 \\
7 \\
\end{array}$ & $\begin{array}{r}7 \\
17 \\
\end{array}$ & $\begin{array}{l}3 \\
3 \\
\end{array}$ & $\begin{array}{c}13+1 \mathrm{DD} \\
11\end{array}$ & $\begin{array}{l}0 \\
4 \\
\end{array}$ & $\begin{array}{l}0 \\
1 \\
\end{array}$ & $\begin{array}{l}11 \\
15\end{array}$ & $\begin{array}{l}\mathrm{A} 13, \mathrm{~S} 1 \\
\mathrm{~A} 13, \mathrm{~S} 2, \mathrm{~B} 2\end{array}$ & $\begin{array}{l}9 \\
8 \\
\end{array}$ & $\begin{array}{l}24 \\
19 \\
\end{array}$ \\
\hline & Total & . & 81 & $44 / 34$ & 13 & 24 & 6 & 25 & 4 & 1 & 26 & A26 & 17 & 21 \\
\hline
\end{tabular}

TABLE II.-Operative Findings in the Various Groups, the Procedures Adopted, and the Number of Deaths which Occurred in Each Group

\begin{tabular}{|c|c|c|c|c|c|c|c|c|c|c|c|c|c|c|}
\hline & & & \multirow{3}{*}{$\begin{array}{l}\text { Total } \\
\text { No. }\end{array}$} & \multirow{3}{*}{$\begin{array}{l}\text { Operation } \\
\text { No. }\end{array}$} & \multicolumn{5}{|c|}{ Operative Findings } & \multicolumn{3}{|c|}{ Procedure } & \multicolumn{2}{|c|}{ No of Deaths } \\
\hline & & & & & \multicolumn{2}{|c|}{ Chronic } & \multirow{2}{*}{ Acute } & \multirow{2}{*}{ Cancer } & \multirow[b]{2}{*}{ Nil } & \multirow{2}{*}{$\begin{array}{l}\text { Partial } \\
\text { Gastrec. }\end{array}$} & \multirow[b]{2}{*}{ Minimal } & \multirow[b]{2}{*}{ Other } & \multirow[b]{2}{*}{ Operation } & \multirow[b]{2}{*}{ Non-op. } \\
\hline & & & & & D.U. & G.U. & & & & & & & & \\
\hline \multirow[t]{2}{*}{ Male } & $\left\{\begin{array}{l}\text { Under } 60 \\
60+\ldots\end{array}\right.$ & 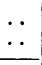 & $\begin{array}{l}95 \\
47 \\
\end{array}$ & $\begin{array}{r}24 \\
8 \\
\end{array}$ & $\begin{array}{l}6 \\
4 \\
\end{array}$ & $\begin{array}{l}5 \\
3 \\
\end{array}$ & $\begin{array}{r}12 \\
1\end{array}$ & $\begin{array}{l}0 \\
0 \\
\end{array}$ & $\begin{array}{l}1 \\
0\end{array}$ & $\begin{array}{r}11 \\
7\end{array}$ & $\begin{array}{r}12 \\
1 \\
\end{array}$ & $1^{*}$ & $\begin{array}{l}\mathbf{0} \\
\mathbf{2} \\
\end{array}$ & $\begin{array}{l}0 \\
2\end{array}$ \\
\hline & ¿ Total & .. & 142 & 32 & 10 & 8 & 13 & 0 & 1 & 18 & 13 & 1 & 2 & 2 \\
\hline \multirow[t]{2}{*}{ Female } & $\left\{\begin{array}{l}\text { Under } 60 \\
60+\ldots\end{array}\right.$ & 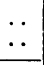 & $\begin{array}{l}38 \\
43 \\
\end{array}$ & $\begin{array}{l}9 \\
8 \\
\end{array}$ & $\begin{array}{l}4 \\
2 \\
\end{array}$ & $\begin{array}{l}1 \\
2 \\
\end{array}$ & $\begin{array}{l}4 \\
2 \\
\end{array}$ & $\begin{array}{l}0 \\
1 \\
\end{array}$ & $\begin{array}{l}0 \\
1 \\
\end{array}$ & $\begin{array}{l}7 \\
4 \\
\end{array}$ & $\begin{array}{l}2 \\
4 \\
\end{array}$ & $=$ & $\begin{array}{l}0 \\
1 \\
\end{array}$ & $\begin{array}{l}0 \\
2 \\
\end{array}$ \\
\hline & Total & $\therefore$ & 81 & 17 & 6 & 3 & 6 & 1 & 1 & 11 & 6 & - & 1 & 2 \\
\hline
\end{tabular}


Surgery, when undertaken, is directed to controlling haemorrhage and not to curing peptic ulceration. The operation of gastrectomy in elderly-or even young-patients who have been exsanguinated has a mortality neither inconsiderable nor confined to the immediate intervention. We have seen "successful" gastrectomy for bleeding followed in later convalescence by death from cardiovascular disease, pulmonary embolus, and renal failure. The widespread practice of equating surgical treatment with gastrectomy-sometimes " blind "has led to the decision for surgery being often unduly delayed, repeated exsanguination and transfusion causing marked fluctuation in the circulatory state of the patient. To these disadvantages must be added the undesirability of resecting a large part of the stomach for what may well turn out to be an acute ulcer $0.5 \mathrm{~cm}$. in diameter and the further fact that this ulcer not infrequently lies too high to be included in the resection normally carried out in performing a "blind" gastrectomy. It may be that in most cases of chronic ulcer a major surgical procedure is necessary in order safely to control bleeding: but in our series $40 \%$ of ulcers were relatively acute and the bleeding was arrested by the rapid and simple process of underrunning the bleeding vessel. It is, of course, well known that peptic ulcer exhibits "territorial" differences in its character and its locale (Tidy, 1944), and Gordon-Taylor (1946) felt that this "territorial" difference might play some part in explaining the different numbers of operations which are performed by different surgeons. It may in fact be that in our part of Essex there is an unusually high incidence of acute or subacute gastric ulcer as a cause of severe haemorrhage. There is, however, no doubt that many ulcers of this kind are missed because a practice is not made of opening the stomach, or, if it is opened, it is not opened sufficiently widely, and use is not made of palpation with the finger-tips as an aid to the difficult task of locating the ulcer by eye.
The guiding principle of surgical treatment in emergency has always been to carry out the least procedure which will save life. In the case of bleeding from peptic ulcer the simplest method should be used which will suffice to control the haemorrhage. In the present series it is this principle which has been followed. The overall mortality of $3.1 \%$ compares favourably with that of other series (Avery Jones, 1947 ; Herdson, 1960 ; Bowers and Gompertz, 1962).

\section{Summary}

In a five-year period 223 patients with severe haematemesis and melaena have been treated. Initial treatment was conservative. Operation was undertaken if haemorrhage persisted or recurred. The decision to operate was made on the clinical state of the patient whether the causative ulcer was believed to be acute or chronic.

There were 49 operations. When a chronic ulcer was found, partial gastrectomy was generally performed. In 19 cases a wide gastrotomy was done and revealed a previously impalpable ulcer, bleeding from which was controlled by underrunning the bleeding-point.

The overall mortality was $3.1 \%$.

\section{REFERENCES}

Bowers, R. F. and Gompertz, M. L. (1962). Ann. Surg., 155, 481. Chandler, G. N. (1960), Postgrad. med. F., 36, 762

Cameron, A. D., Nunn, A. H., and Street, D. F. (1960). Lancet, 2, 507 .

Gordon-Taylor, G. (1946). Brit. 7. Surg., 33, 336.

Gordon-Taylor, G. (1946). Brit. f. Surg., 33,

Jones, F. A. (1947). Brit. med. f., 2, 441.

Meulengracht, E. (1935). Lancet, 2, 1220.

Osborn, G. R. (1954). Brit. F. Surg., 41, 585.

Tidy, Sir Henry (1944). Proc. roy. Soc. Med., 38, 95.
Many procedures in the management of haemorrhage from the upper gastro-intestinal tract have until recently been largely empirical. With the development of new diagnostic techniques, however, it has been possible to make an early appraisal of the source of bleeding. If the site of bleeding is thus located the rational management of such patients is facilitated, since there are important differences in the natural history of haemorrhage from a chronic peptic ulcer, from an acute gastric erosion, or from oesophageal varices, the three major causes of bleeding from the upper gastro-intestinal tract.

Measurement of the nocturnal gastric-acid secretion (Chandler and Watkinson, 1953) and early radiological investigation (Knowles et al., 1952 ; Chandler et al., 1960a ; Oneal and Hirsh, 1962 ; Cummack, 1964) have been shown to be useful diagnostic aids. Chandler et al. (1960b) added

* University Department of Medicine, Gardiner Institute, Western Infirmary, Glasgow.

t Department of Radiology, Western Infirmary, Glasgow.

\$ University Department of Surgery, Western Infirmary, Glasgow. Present address: Department of Surgery, University of Queensland, Brisbane Hospital, Berston, Brisbane, Queensland, Australia. gastroscopy to these tests in order to locate the site of bleeding in the first 24 hours of admission. More recently Burnett (1962) and Hirschowitz et al. (1963) have evaluated the use of the gastroduodenal fibrescope in detecting the site of bleeding. An even more urgent requirement in the management of these emergencies is the assessment of blood loss. To this end Tibbs (1956), using the Evans-blue technique, and Tudhope (1958), with radiochromium- $\left({ }^{51} \mathrm{Cr}\right)$-labelled erythrocytes, measured blood volumes and correlated the assessed blood loss with the clinical state of the patient.

In the present study such diagnostic techniques have been integrated in order to facilitate a more rational approach to management in a group of patients with haemorrhage from the upper gastro-intestinal tract. Throughout, the physician and the surgeon jointly planned investigation and treatment of the patient. A rapid assessment of blood loss has been made with radioiodinated $\left({ }^{13} \mathrm{I}\right)$ human serum albumin, and this has been correlated with the clinical state of the patient. An attempt has been made to locate the site of bleeding within the first 24 hours of admission by means of (a) clinical history and 